\title{
WHAT DO CZECH ADOLESCENTS KNOW ABOUT HIV?
}

\author{
Veronika Mičulková1, ${ }^{1}$, Alena Fialováa, Tanja Kovačič ${ }^{1,4}$, Lidmila Hamplová5, Dan Veselý ${ }^{6}$, Petr Hulínský4 \\ ${ }^{1}$ Centre for Public Health Promotion, National Institute of Public Health, Prague, Czech Republic \\ ${ }^{2}$ Department of Public Health, Medical Faculty, Masaryk University, Brno, Czech Republic \\ ${ }^{3}$ Department of Biostatistics, National Institute of Public Health, Prague, Czech Republic \\ ${ }^{4}$ Department of Ethnology and Cultural Anthropology, Faculty of Arts, University of Ljubljana, Ljubljana, Slovenia \\ ${ }^{5}$ Department of Health Care Specialization, Medical College, Prague, Czech Republic \\ ${ }^{6}$ Clinic of Infectious, Tropical and Parasitic Diseases, Hospital Na Bulovce, Prague, Czech Republic
}

\section{SUMMARY}

Objective: During last years, a significant increase of HIV infection transmitted through sexual intercourse among young adults has been reported in the Czech Republic. The issue of prevention, where sexual education belongs to an important preventive tool, is much more topical than ever before. The level of knowledge and attitudes related to HIVIAIDS among adolescents has not been assessed so far. The aim of our study was to explore this field in a nationally representative sample.

Methods: Information was obtained using an anonymous questionnaire that was filled in by 1,627 adolescents 13 to 15 years old selected from a representative sample of 25 elementary and grammar schools in the Czech Republic.

Results: Based on the survey results, good knowledge regarding primary HIVIAIDS prevention was noted in the majority of respondents who however tended to stigmatize HIV positive people.

Conclusion: The study has confirmed the importance of school as the main source of information (reported by $50.8 \%$ of respondents). The result of our study can serve as a starting point in assessment and comparison of the effect of various educational programmes.

Key words: HIV, AIDS, prevention, knowledge, primary prevention, stigma

Address for correspondence: V. Mičulková, Centre for Public Health Promotion, National Institute of Public Health, Šrobárova 48, 10042 Prague 10, Czech Republic. E-mail: veronika.miculkova@szu.cz

https://doi.org/10.21101/cejph.a4929

\section{INTRODUCTION}

Though the Czech Republic is still ranked as country with a relatively low HIV prevalence, there has been an alarming increase of newly diagnosed cases observed since 2003. Contrary to $63 \mathrm{HIV}$ positive cases reported in 2003, there were 232 newly infected people detected in 2014 (1). The issue of prevention of this incurable disease is getting more urgent than ever.

Sexual education presents a substantial part of primary prevention of HIV infection. Effectively conducted programmes can substantially contribute to abstinence or delay of the onset of sexual life, they could further lower the frequency of unprotected sexual intercourse, decrease number of sexual partners, and support the usage of protective tools in order to prevent unwanted pregnancy, and to assist in prevention of sexually transmitted diseases as well. School environment provides an important opportunity to address a great number of young people before the initiation of sexual life (2).

The basics of sexual education, including HIV prevention, are embedded in a document of the Ministry of Education, in the Framework of Educational Programme for Basic Education (3). Activities supporting prevention among young are also anchored in a strategical document the National HIV/AIDS
Programme in the Czech Republic compiled by the Ministry of Health (4).

Information on a realization of HIV/AIDS preventive activities is provided in the last Yearbook of the National HIV/AIDS Programme for the period of 2013-2014. In 2014, the following preventive activities were registered for external collaboration with schools: the most frequent programme "Game against AIDS" addressed in total 6,321 adolescents, and other topical lectures were attended by 6,976 adolescents. Besides that, according to estimates more than 218,000 adolescents from 402 schools saw preventive video spots within the project "School informative channel". We assume that a real number of realized activities was much higher (5).

Except for an orientational overview of preventive activities, we have only very limited information on informative literacy of adolescents in this area. So far, only few papers focused on HIV/AIDS knowledge in Czech schools. The most relevant source of information provided so far are results presented in the study by Wasserbauer (6) carried out in elementary and high schools in Jihlava region. Other information is available in bachelor and diploma theses evaluating knowledge of the above subject in students attending high school or healthcareoriented schools $(7,8)$. 
The aim of our study was to overcome those gaps and to explore a present-day level of knowledge and attitudes related to HIV/AIDS among young adolescents in a sample representative for the Czech Republic, as well as to enable the comparison and assessment of educational programmes effectivity in the future.

\section{MATERIALS AND METHODS}

\section{Sample}

The target group of our study consisted of pupils attending the 7th and 8th grade of elementary schools and students of corresponding grades attending grammar schools randomly chosen from schools in the Czech Republic. In total 1,627 adolescents from 25 schools participated in our study.

In school selection, the sort of school (elementary or grammar school), size of the municipality and the Nomenclature of Units for Territorial Statistics (NUTS) II region, where the school was situated, were taken into account to provide a representative sample. For school selection, we used the Register of schools and school facilities enabling a selection of school based on the type of school and the region (9). After addressing 34 schools, 9 of them rejected participation. After the rejection, another school from the list was addressed; this school was of the same type in the same size of the municipality and the region. The most common reason for refusal of participation was insufficient time or the clash of other extraordinary school activities (other studies, school inspection).

Our sample consisted of 794 boys $(48.80 \%)$ and 786 girls (48.31\%) while 47 respondents $(2.89 \%)$ did not reported their gender. Representation of pupils according to the grade was balanced: 565 pupils (34.7\%) attended the 7 th grade, 535 pupils (32.9\%) attended the 8 th grade and 527 pupils (32.4\%) attended the 9 th grade or an adequate grade of a grammar school.

\section{Methods}

For exploring information on HIV/AIDS, we created an anonymous questionnaire including basic information on respondent's gender, school and age of respondents. In the first part, altogether 21 questions were concentrated on knowledge of HIV/AIDS. During questionnaire development, we followed the Global AIDS Response Progress Reporting (GARPR) system (10), and we also used questions from the previous study conducted in Jihlava region (6). Out of given choices, only one was correct with gain of one point for a respondent.

Regarding the domain concerning attitudes towards people living with HIV, two questions from the GARPR system (10) were used with answer option yes, no, I don't know with range $0-2$ of points to gain. Questioning was closed with inquiry about the source of information and two more questions regarding behaviour.

Giving instructions and collecting anonymous questionnaires filled in by adolescents was provided by health professionals from the National Institute of Public Health in the class within the presence of teachers. After the heads of school consent was obtained data collection was realized during the period from March to June 2015. The filling in a questionnaire took approximately 15 to 20 minutes.

\section{Statistics}

All statistical analyses were conducted using SPSS 23.0. (SPSS Inc., Chicago, IL, USA). As the data did not meet the assumptions of normal distribution, nonparametric methods were used to test differences. Differences among groups were evaluated using the median test, Kolmogorov-Smirnov test, Pearson's Chi-Square test, Kruskal-Wallis or Mann-Whitney U test. Statistical significance was set at $\alpha=0.05$ (two-side).

\section{RESULTS}

\section{Knowledge}

In the area of knowledge, it was possible to obtain $0-21$ points. An average score from 1,627 questionnaires was 14.71 points, median 15 points. The knowledge score had an increasing trend in higher grades: in the 7th grade and corresponding grade in grammar school it reached 13.1 points (median 13 points), in the 8th grade 15.1 points (median 15 points) and in the 9th grade 16.0 points (median 17 points) (Fig. 1). The knowledge of adolescents was significantly dependent $(\mathrm{p}<0.001)$ on the grade attended. The knowledge of adolescents was not dependent on gender and the size of the municipality where the school was situated. Similarly, there was no difference between pupils from schools taking part in the "School Supporting Health" programme and other schools. Knowledge scores between pupils from elementary schools and students from grammar schools were significantly different, students from grammar schools had a higher score on average (1.33 points difference).

The most common mistake was an incorrectly assessed time: how long after after a risky behaviour a man should take a test (correct answers 11.3\%) and what the post-exposure prophylaxis is (correct answer 14.6\%). On the other hand, more than $90 \%$ of adolescents knew that even a healthy-looking man can be HIV positive $(90.5 \%)$, that HIV is transmissible throug sexual intercourse $(97.3 \%)$, blood $(93.3 \%)$, sharing needles $(92.1 \%)$, and it is not transmissible by hugging $(95.0 \%)$.

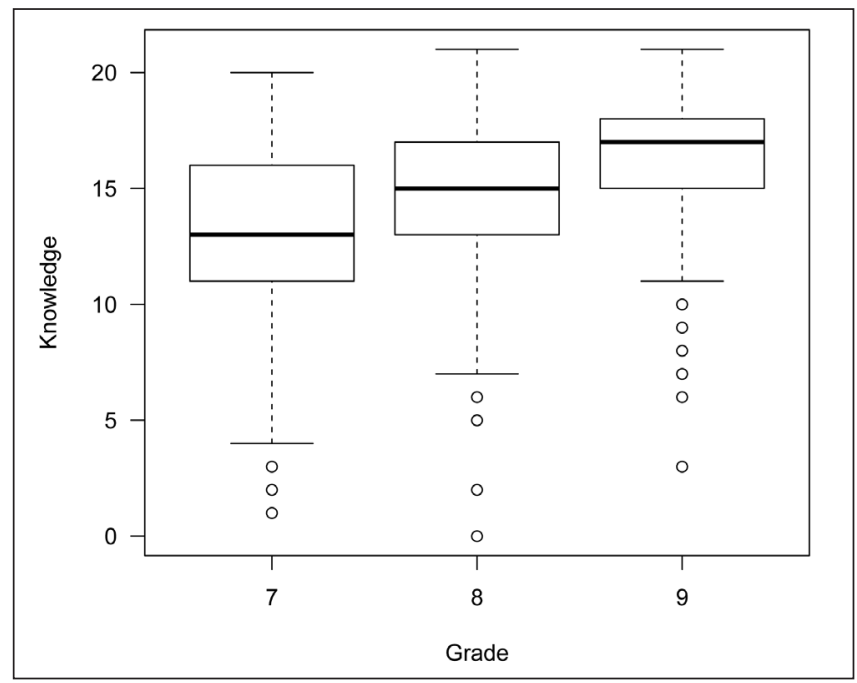

Fig. 1. Knowledge score (0 - 21 points) in dependency to the respondent's grade.

The higher the knowledge score, the better the knowledge. 
Table 1. The list of all question on HIVIAIDS knowledge, correct answers, number of respondents that answered correctly, inclusive of their percentage share from the whole sample $(N=1,627)$

\begin{tabular}{|c|c|c|c|}
\hline Question & Correct answer & $\begin{array}{l}\text { Number of correct } \\
\text { answers }\end{array}$ & $\begin{array}{l}\text { Percentage of correct } \\
\text { answers }\end{array}$ \\
\hline What is HIV? & virus that causes AIDS & 1,121 & 70.0 \\
\hline What is AIDS? & $\begin{array}{l}\text { acquired immunodefi- } \\
\text { ciency syndrome }\end{array}$ & 1,053 & 66.7 \\
\hline Can a person, who looks healthy, be HIV positive? & yes & 1,444 & 90.5 \\
\hline \multicolumn{4}{|l|}{ Which of the following routes of HIV transmission is possible? } \\
\hline Sexual intercourse & yes & 1,579 & 97.3 \\
\hline Insect bite & no & 1,119 & 69.9 \\
\hline Handshake & no & 1,413 & 88.1 \\
\hline Shared use of WC & no & 823 & 51.6 \\
\hline Blood & yes & 1,494 & 93.3 \\
\hline Shared use of injection needles & yes & 1,485 & 92.1 \\
\hline Common kiss & no & 1,076 & 67.1 \\
\hline From HIV positive mother to child & yes & 1,118 & 69.9 \\
\hline By hugs & no & 1,527 & 95.0 \\
\hline Mutual washing of dirty laundry & no & 1,389 & 86.4 \\
\hline $\begin{array}{l}\text { Can the risk of HIV transmission be reduced if the person has inter- } \\
\text { course with only one partner who has not HIV and has no other sexual } \\
\text { partners? }\end{array}$ & yes & 1,108 & 68.6 \\
\hline $\begin{array}{l}\text { Can a person reduce the risk of HIV infection by using a condom during } \\
\text { every sexual intercourse? }\end{array}$ & yes & 1,345 & 83.2 \\
\hline $\begin{array}{l}\text { Can a person already be infected with HIV during the very first sexual } \\
\text { intercourse? }\end{array}$ & yes & 1,336 & 82.4 \\
\hline Does the hormonal contraception protect against HIV infection? & no & 1,051 & 65.1 \\
\hline Who can be a source of HIV infection? & HIV positive person & 961 & 61.4 \\
\hline $\begin{array}{l}\text { How long after the risky situation should a person be tested for HIV, so } \\
\text { that the result was reliable? }\end{array}$ & after 2-3 months & 183 & 11.3 \\
\hline Is it possible to completely cure an HIV infection? & no & 1,067 & 66.0 \\
\hline What does a post-exposure prophylaxis mean? & $\begin{array}{l}\text { drug application after a } \\
\text { risky situation }\end{array}$ & 234 & 14.6 \\
\hline
\end{tabular}

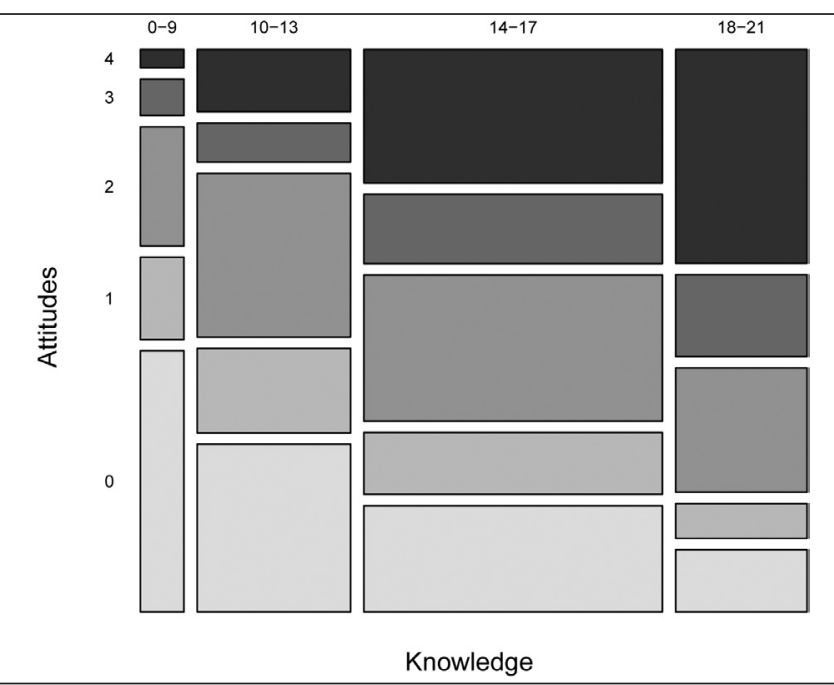

Fig. 2. Mosaic plot of respondent's attitudes towards people living with HIV $(0-4$, where 0 represents the least friendly attitudes towards people with HIV) in dependency on knowledge score $(0-21$ points for questions on knowledge).
The list of knowledge questions, correct answers, numbers, and percentages of correct answers is presented in Table 1.

\section{Attitudes towards People Living with HIV}

Attitudes towards people living with HIV were investigated by two following questions: "Would you buy fresh vegetable from a HIV positive seller?" this question was answered positively by less than one third of pupils (500 adolescents, 31.0\%), 797 adolescents (49.4\%) responded no and $316(19.6 \%)$ responded I don't know.

The second question: "Do you think that HIV positive children should be able to attend school together with children that are HIV negative?" was answered yes by around a half of children (837 adolescents, $52.2 \%), 491$ adolescents $(30.6 \%)$ responded no and 275 adolescents $(17.2 \%)$ I don't know.

Respondent's attitudes positively correlated with their knowledge on HIV/AIDS - the better the knowledge, the more friendly attitudes towards HIV positive people. The relationship between knowledge and attitudes of respondent is shown in Fig. 2. The 
median of knowledge score was significantly different $(\mathrm{p}<0.001)$ between groups of adolescents with the attitude score.

\section{Source of Information}

The question "Do you think you have enough information on HIV/AIDS?" was responded negatively by the majority of adolescents (669 adolescents, 41.6\%), 495 adolescents (30.8\%) responded positively and 444 adolescents $(27.6 \%)$ did not know.

HIV/AIDS was the most frequently mentioned topic in schools, once reported by 686 pupils (43.1\%) and more than once reported by 451 adolescents $(28.3 \%)$. In total 455 participants $(28.6 \%)$ reported that the topic of HIV/AIDS has not been mentioned in schools at all. The total of 131 adolescents $(8.2 \%)$ reported participation on the most frequent primary preventive programme "Game against AIDS".

Approximately a half of adolescents ( 826 adolescents, 50.8\%) reported school as the main source of information on HIV/AIDS. Internet (524 adolescents, 33.3\%), family (280 adolescents, $17.2 \%$ ), friends (119 adolescents, 7.3\%), and other sources (184 adolescents, $11.3 \%$ ) followed as other sources of information. There was a significant difference in knowledge score in relationship to the source of information. Pupils with main informative source from school, internet and family had better knowledge than pupils with information from their friends.

\section{Behaviour}

The question: "Do you behave safely, not to be infected with HIV?" was answered yes by three quarters of adolescents (214 adolescents, $75.2 \%$ ). No was the response of 87 adolescents (5.4\%) and the answer I don't know was reported by 313 adolescents $(19.4 \%)$.

The total of 923 adolescents (57.4\%) think that they know how to protect themselves against HIV transmission compared to 170 adolescents (10.6\%) who do not believe that and 515 adolescents $(32 \%)$ who do not know whether they can protect themselves. With the increasing grade, there was a significantly higher share $(p<0.001)$ of adolescents believing that they can protect themselves and the share of adolescents with the opposite opinion or not knowing was lower in our study.

\section{DISCUSSION}

The survey among elementary and high school students in Jihlava region from 2004 appears to be the most relevant reference for a comparison (6). The total of 320 respondents participated in this survey with 153 children from elementary schools. Those adolescents had better knowledge on what AIDS is (83\% vs. $66.7 \%$ in our study), $75.8 \%$ of them knew that HIV is transmissible through blood (vs. $93.3 \%$ ), by sexual intercourse (93.5\% vs. $97.3 \%$ ), by sharing needles and syringes ( $84.3 \%$ vs. $92.1 \%)$. Only $2 \%$ of respondents of that survey thought that HIV is transmissible through kissing (vs. 32.9\% of incorrect answers), less than $1 \%$ by using the same toilet or shower (compared to almost a half of incorrect answers), $71.2 \%$ of participating pupils knew that HIV infection can be reliably detected after $2-3$ months compared to $11.3 \%$ in our study. However, a non-representativeness of the sample and relatively long time elapsed between realization of both studies make it impossible to make any conclusions regarding trends in HIV knowledge levels.

Regarding sources of information in Wasserbauers' survey, pupils from elementary school reported most frequently that they had obtained information from teachers (70.6\%), and then from press, radio or television (6). Hamplova finds that school and schoolbased activities have a primary role as a source of information in $34.2 \%$ of respondents, based on the survey conducted among 640 respondents aged 15-17 years. Approximately for two thirds of young people from the whole sample, the most important first source of information regarding HIV/AIDS were media (34.4\%). The difference in the role of media and school as the first source of information was statistically nonsignificant, however, there was a significantly lower score of family as a source of information in this field $(21.9 \%)$, and a role of peers was even lower in the total sample (9.5\%) (11).

As far as the comparison with findings from similar studies from European countries is concerned, we can see consistent results with the findings from the systematic review on awareness and knowledge on sexually transmitted diseases (STD) among school-going adolescents in Europe: $81-99 \%$ of participants knew that HIV is sexually transmitted (vs. $97.3 \%$ in our study), $68-99 \%$ of participants knew that sharing a needle with an HIV infected person may lead to infection with the virus (vs. $92.1 \%$ in our study) and $51-99 \%$ of participants knew that use of condoms can protect against HIV transmission (vs. $83.2 \%$ in our study) (12). Even though differences in knowledge based on respondent's gender could be found in literature, we did not find general gender-based differences as it was described in a population-based study on knowledge on HIV/AIDS among young adults in Pakistan that represents a socially and culturally different area (13).

As possible limits of this study, the authors perceive a thin profile of the questionnaire, affected by authors' experience, and missing education practice among adolescents (they think that HPV vaccination protects also against HIV infection). Also, not including questions on respondent's sexual and addictive behaviour can be viewed as limiting. There were some practical reasons for not including the above mentioned questions because they would lead to extension of questionnaire, longer time needed to fill it in and lower probability of supportive attitude of heads of schools regarding study participation. Other limiting factor could be the level of participation of addressed schools, that were asked for participation several times via e-mail and phone before contacting other school.

\section{CONCLUSIONS}

Based on the results of survey among 1,627 adolescents, the majority has good knowledge in the area of primary HIV/AIDS prevention (more than $90 \%$ know that even a healthy-looking man can be HIV positive (90.5\%), that HIV is transmitted through a sexual intercourse (97.3\%), blood (93.3\%), sharing needles $(92.1 \%)$, and that it is not transmitted through hugging $(95.5 \%)$. Gaps in knowledge could be seen mainly in secondary or tertiary prevention in incorrect determining of the period when a man should take a test after a risky situation $(11.3 \%$ answered correctly), and also knowledge on post-exposure prophylaxis (only 
$14.6 \%$ of answers were correct). From the total score of 21 points for knowledge answers after answering everything correctly, pupils scored 14.71 points on average. Respondents' knowledge score was higher in higher grades. The knowledge score was not dependent on respondent's gender and a size of a municipality. Respondents from grammar schools reached a higher average score compared with respondents from elementary schools.

In spite of relatively good knowledge in the field of primary prevention, adolescents tended to stigmatize HIV positive people in their views. As the main source of information, school (50.8\% of respondents) together with internet (33\% of respondents) were reported.

The survey has revealed that the majority of adolescent pupils from the highest grades in elementary school and adequate grades in grammar schools has good knowledge in the field of primary prevention, acquired mainly in schools. It is desirable to strengthen this trend by specific programme development and to motivate teachers to implement them. The results give a background for following older adolescents and their sexual behaviour that would enable a targeted screening of people at a higher risk of HIV acquisition.

\section{Acknowledgements}

The authors would like to express thanks to all participating subjects, particularly to the heads of schools that allowed a realization of the survey in their schools, and also to the Centre of Public Health Promotion from the National Institute of Public Health whose employees have collaborated on data administration.

\section{Conflict of Interests}

None declared

\section{Sponsorship}

The survey was financially supported by the Ministry of Health of the Czech Republic.

\section{Adherence to Ethical Standards}

The survey was approved by the Ethical Commission of the National Institute of Public Health.

\section{REFERENCES}

1. Maly M, Nemecek V, Zakoucka H. The prevalence and spread of HIV/ AIDS in the Czech Republic in 2014. Zpr Cent Epidemiol Mikrobiol. 2015 Sep;24(9):294-304. (In Czech.)
2. UNESCO. International technical guidance on sexuality education: en evidence-informed approach for schools, teachers and health educators [Internet]. Paris: UNESCO; 2009 [cited 2016 Sep 2]. Available from: http://unesdoc.unesco.org/images/0018/001832/183281e.pdf.

3. Ministry of Education, Youth and Sports. Framework educational program for basic education [Internet]. Prague: MEYS; 2016 [cited 2016 Sep 2]. Available from: http://www.nuv.cz/uploads/RVP ZV 2016.pdf. (In Czech.)

4. Ministry of Health of the Czech Republic. The National Programme for HIV/AIDS in the Czech Republic during the period 2013-2017 [Internet]. Prague: Ministry of Health of the Czech Republic; 2013 [cited 2016 Sep 2]. Available from: https://www.mzcr.cz/Verejne/dokumenty/ narodni-program-reseni-problematiky-hiv/aids-v-ceske-republice-naobdobi-2013- 75831688 5.html. (In Czech.)

5. Sikolova V, editor. Yearbook of the National HIV/AIDS Programme in the Czech Republic 2013-2014 [Internet]. Prague: National Institute of Public Health; 2015 [cited 2016 Sep 2]. Available from: http://www. prevencehiv.cz/materialy/rocenky/2013/rocenka-2013.pdf. (In Czech).

6. Wasserbauer S. Study of awareness of HIV/AIDS-related issues among students in selected schools in Jihlava. In: Jedlicka J, Kondrova D, Chmelova B, editors. Yearbook of the National HIV/AIDS Programme in the Czech Republic 2003-2004 [Internet]. Prague: National Institute of Public Health; 2004 [cited 2016 Sep 2]. p. 24-30. Available from: http://www.prevencehiv.cz/materialy/rocenky/2004/ rocenka-2004.pdf. (In Czech.)

7. Bojanovska K. AIDS cognitive scheme, attitudes and prevention among secondary school students [dissertation]. Pardubice: University of Pardubice; 2010. (In Czech.)

8. Keilova B. Awareness of HIV/AIDS among secondary school students in the Jablonec area [disertation]. Pardubice: University of Pardubice; 2010. (In Czech.)

9. Index of schools and school facilities [Internet]. Prague: Ministry of Education, Youth and Sports [cited 2016 Sep 2]. Available from: http:// rejskol.msmt.cz/. (In Czech.)

10. Global AIDS response progress reporting 2014: construction of core indicators for monitoring the 2011 United Nations political declaration on HIV and AIDS [Internet]. Geneva: UNAIDS; 2014 [cited 2016 Sep 2]. Available from: http://www.unaids.org/sites/default/files/media_asset/ GARPR 2014 guidelines en 0.pdf.

11. Hamplova $\mathrm{L}$. The role of health services in the area of health promotion in implementing regional health policies [dissertation]. Bratislava: St. Elisabeth University of Health Care and Social Work; 2010.

12. Samkange-Zeeb FN, Spallek L, Zeeb H. Awareness and knowledge of sexually transmitted diseases (STDs) among school-going adolescents in Europe: a systematic review of published literature. BMC Public Health. 2011 Sep 25;11:727. doi: 10.1186/1471-2458-11-727.

13. Farid-ul-Hasnain S, Johansson E, Krantz G. What do young adults know about the HIV/AIDS epidemic? Findings from a population based study in Karachi, Pakistan. BMC Infect Dis. 2009 Mar 26;9:38. doi: 10.1186/14712334-9-38. 